\title{
COLLOQUIUM IN COMBINATORIAL THEORY, ROME
}

From September 3-15, 1973 there was held a Colloquio Internazionale sulle Teorie Combinatorie, in Rome sponsored jointly by the Accademia Nazionale dei Lincei (National Academy of the Lynx) of Rome, and the American Mathematical Society. The organizing committees designated by the two sponsors consisted of Professors Beniamino Segre (Chairman), Enrico Bombieri, Lucio Lombardo-Radice, Giovanni Ricci, Giuseppe Tallini, Guido Zappa, and Adriano Barlotti representing the Accademia, while Professors Marshall Hall, Jr., (Chairman), Gian-Carlo Rota, William T. Tutte and Bruce Rothschild were designated by the Society.

Approximately sixty-five invited participants were in attendance, from more than a dozen countries. The scientific program was divided into twenty-two sessions of invited talks, each being either of one-hour or thirty-minute duration. In addition, about 25 contributed short communications were delivered. All sessions were held in the Palazzo Corsini (via della Lungara, 10), a Palace which has been the home of the Accademia since 1883 .

The opening session, on the morning of September 3, featured a welcoming address by the Colloquium Chairman, Professor Beniamino Segre, as well as addresses by Professors Marshall Hall, Jr., (Construction of combinatorial designs) and Kazimierz Kuratowski (My personal recollection connected with research on some topological problems).

A complete list of speakers, named in order of their presentations, is as follows: S. S. Shrikhande, Thomas Brylawski, R. Cori, Neil White, William Bridges, Paul Erdös, Richard Rado, Dominique Foata, Ralph G. Stanton, Indra-Mohan Chakravarti, Curtis Greene, William Kantor, Giovanni Ricci, William T. Tutte, Bruce Rothschild, Christoph Hering, Judita Cofman, Ferenc Kárteszi, James W. P. Hirschfeld, Dina Smit Ghinelli, Emanuel Sperner, Gian-Carlo Rota, Jacques Tits, Herbert Wilf, Richard A. Brualdi, Marcel P. Schützenberger, Thomas A. Dowling, Richard M. Wilson, Günter Pickert, Richard Hubert Bruck, Jean Doyen, Beniamino Segre, Lucio Lombardo-Radice, Guiseppe Tallini, Ray C. Bose, Francis Buekenhout, Adriano Barlotti, Rudolf Wille, Lawrence H. Harper, Branko Grünbaum, Richard K. Guy, Friedriçh Bachmann, Paul Turán, Johannes André, Cesarina Marchionna Tibiletti, G. Neil Robertson, Basil Gordon, Vera Turán, Daniel Hughes, Haim Hanani, Herbert J. Ryser, Claude Berge, Henry Crapo, Gabriel Andrew Dirac, J. J. Seidel, Alan J. Hoffman, Guido Zappa, H. Lüneburg, Luigi Antonio Rosati, Maria Tallini Scafati, D. K. Ray Chaudhuri, Enrico Beltrametti, E. R. Caianiello.

Living expenses of invited participants were borne by the Accademia, which also arranged a visit to the ancient Etruscan city of Orvieto, on Saturday, September 8, for the speakers and their families.

Proceedings of the Colloquium will be published as soon as possible.

New YORK CiTY

SEPTEMBER 19, 1973

Herbert S. WiLF 